\title{
Fouling microorganisms in the reservoirs of the groundwater treatment system
}

\author{
Zoia Litvinenko $^{1 *}$, Liubov Kondratyeva ${ }^{1}$, and Evgenia Golubeva ${ }^{2}$ \\ ${ }^{1}$ Institute of water and ecology problems, Far East Branch, Russian Academy of Sciences, 680000 Khabarovsk, Russia \\ ${ }^{2}$ Institute of Tectonics and Geophysics, Far East Branch, Russian Academy of Sciences, 680000 Khabarovsk, Russia
}

\begin{abstract}
The work discusses the features of the structure of fouling (biofilms) formed in the water treatment system of the iron-bearing groundwater of the Tungusskii deposit (Far East, Russia). The main factors affecting the composition of biofilms are trace amounts of organic substances, oxygen, different phylogenetic composition of microbial communities and their ability to form a polysaccharide matrix. The formation of structured communities in biofouling of the water treatment system can have a negative impact on the organoleptic characteristics of drinking water due to the formation of complex trophic connections.
\end{abstract}

\section{Introduction}

Currently, according to the WHO data [1], biofouling (biofilms) is often formed in distribution systems at the stage of water treatment, which is a risk factor for human health and can affect the hydraulic characteristics of the water supply system. Drinking water quality is a priority research area all over the world [2]. Due to the chronic pollution of surface water sources, more attention is paid to groundwater. Groundwater treatment methods are constantly being improved and include the use of integrated approaches and the development of new technologies, taking into account regional specifics [3, 4]. Relevance of the water treatment methods study is due to the increased interest in iron-containing groundwater and the possibility of their use for drinking needs, excluding the use of toxic reagents. Negative factors that can affect the quality of groundwater are associated with biofouling of equipment. At every stage of water treatment, including the pore space of the aquifer, near the filter zone, wells, surface distribution systems and water reservoirs, there is a risk of microbial consortia formation.

Final stage of groundwater treatment in some surface installations includes the use of a decarbonizer (DC) and reservoir of clean water (RCW) in the technological chain. This equipment is also susceptible to biofouling due to a decrease in hydraulic flow in the water treatment network $[5,6]$. Insufficient knowledge of biofilms, as well as the mechanisms of their formation on technological equipment in the water treatment system, enhance the practical significance of researches on structure of biofilms and properties of microorganisms participating in biofouling. These studies allow predicting possible undesirable effects, including well clogging and deterioration of drinking water quality due to biofilm metabolism products.

Purpose of the manuscript was to study the microstructure of biofilms formed in decarbonizer and a reservoir of clean water in the ground water treatment system of the Tungusskii iron-bearing groundwater deposit (Amur River Basin).

\section{Methods and materials}

Tungusskii groundwater deposit is located in the central part of the Middle Amur artesian basin, Far East of Russia. The geological structure of the Tungusskii deposit includes coal-bearing Lower Miocene deposits of the Ushumun Formation (siltstones, mudstones, with beds of brown coals, sands and breccia lenses) and Upper Miocene-Quaternary alluvial deposits, represented by sands, gravels with pebbles and sandy aggregates. Subterra technique is applied as a pre-treatment step in the pristine groundwater to control elevated $\mathrm{Fe}$ and $\mathrm{Mn}$ concentrations. All production wells alternately serve as infiltration and extraction wells [7, 8].

Main stages of water treatment at the Tungusskii water intake include several processes (Fig.1). Saturation of water from the well with oxygen carried out in a decarbonizer (DC) through a system of aerators. Oxygenated water is pumped through the well into the aquifer and creates the iron and manganese oxidation zone. After a certain period of time, purified water begins to rise from the well enriched with oxygen, which is collected in clean water reservoirs $(\mathrm{RCW})\left(\mathrm{V}=10000 \mathrm{~m}^{3}\right)$. After disinfection with ultraviolet irradiation and sodium hypochlorite, the water is transported to the consumer.

\footnotetext{
* Corresponding author: zoyalitvinenko@gmail.com
} 


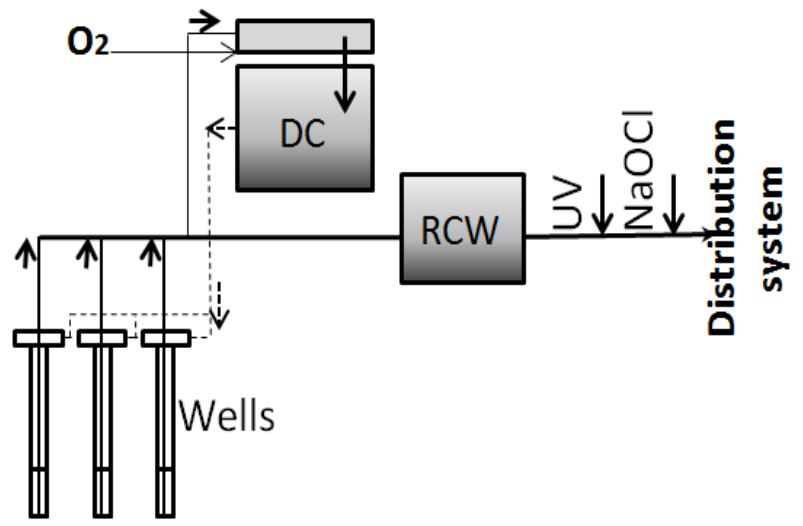

Fig.1. Diagram of the water treatment at the Tungusskii groundwater intake (www.vodocanal.org).

Objects of investigation are fouling microorganisms from biofilms formed in the main equipment (decarbonizer - orange flocculent biomass; reservoir of clean water - gray pasty biomass) of the treatment system of the Tungusskii groundwater deposit.

Microbiological investigation of biofilms samples from technological chain was carried out with use of cultivation on solid nutrient medium: starch-ammonia agar (SAA), fish peptone agar (FPA), and FPA with tenfold diluted nutrients concentration (FPA: 10). Ironmanganese bacteria were determined on solid Bromfield's medium. Food requirements of the isolates from biofilms were determined in liquid Bromfield's medium with different carbon sources (peptone $2 \mathrm{~g} / \mathrm{L}$, lactate $2 \mathrm{~g} / \mathrm{L}$, glucose $3 \mathrm{~g} / \mathrm{L}$, sodium humate $0,025 \mathrm{~g} / \mathrm{L}$ ). Cultivation was carried out in three replicates for 7 days at $20-23^{\circ} \mathrm{C}$.

Molecular genetic analyzes were determined by quantitative PCR performed with an of Rotor-Gene 60005 Plex real-time DNA cycler (Germany). Total numbers of eubacterial DNA copies and number of the DNA copies of Rhodoferax, Gallionella, Crenothrix and Geothrix were determined with use of specialized primers developed in the Technical University of Berlin by Prof. Ulrich Szewzyk and his team [9]. Parameters for the calibration curves: $\mathrm{R}^{2}>0.99$, efficiency $92-98 \%$. Quantitative PCR was carried out according to the generally accepted protocols. DNA was isolated with use of the Gene Matrixsoil DNA purification kit, according to the manufacturer's recommendations (EUR x Ltd., Germany). Samples of the culture liquid were filtered through $0.2-\mu \mathrm{m}$ cellulose acetate membranes (Sartorius stedium, Germany). Light microscopy examination of Gram stained smears of biofilms and isolated strains was performed with use of Imager-A2 fluorescent microscope (Carl Zeiss, Germany).

Microstructure of the biofilms were studied on EVO40HV (Carl Zeiss, Germany) in the secondary electrons mode with platinum deposition coupled to an X-MAX 80 mm 2 silicon drift X-rye detector at the Analytical Center of the Institute of Tectonics and Geophysics, Far Eastern Branch, Russian Academy of Sciences, analyst Konovalova N.S.

\section{Results and discussion}

Groundwater which came from the wells to the water treatment plant has different composition and dominant microorganisms. It contains both autochthonous (microorganisms from the aquifer and pore space) and allochthonous (soil, entering with surface waters) representatives. As a result of changes in environmental conditions and impact of physicochemical factors, adaptation and selection of individual groups of microorganisms occurs by the way of formation of communities (consortia), united by a polymer substrate in biofilms. The dominance of certain types of microorganisms is due to the changing composition of the pumped out water and the oxygen content.

According to molecular genetic studies of Germany scientists from the Berlin Technical University, [9], the community microbiocenoses from the groundwater of the Tungusskii water deposit includes bacteria exhibiting different ecological strategies. Among them are phyla Proteobacteria, Actinobacteria, Bacteroidetes, et al. Large variations in the bacterial community structure were observed in the different well water samples from operating and non operating wells. In the course of well operation, the population changed to a high diverse community structure, where Gallionella, Rhodoferax, Crenothrix, Actinobacteria ACK-M1, Methylotenera OTUs were presented. Presence of these microorganisms in the studied biofilms formed in technological chain is obvious due to the entering groundwater to the DC and RCW immediately after pumping out from the aquifer. Total quantitative content of eubacterial gene copies in water samples from RCW was $81 \times 10^{8}$ DNA copies $/ \mathrm{mL}$. Additional analysis of qPCR with use of various primers confirmed the presence of Rhodoferax, Gallionella, Crenothrix, and Geothrix species in the structure of biofilm sampled in DC and RCW. Many of them are directly involved in the iron and manganese cycle.

\subsection{Research of cultivated microbial communities}

Microbiological inoculation of biofilms on agar media of different composition showed significant differences in the structure of microbial complexes (MC) that formed biofilms. Thus, the biofilm from DC was represented by various types of pigmented colonies (orange, pink, yellow). The structure of the biofilm sampled from the bottom of the RCW was not as diverse as in the DC. It also contained several morphotypes of colonies, among which yellow slimy colonies predominated, preferring diluted nutrient medium with nitrogen-containing organic substances (FPA:10) and growing on starch with ammonium nitrogen (SAA). Depleted nutrient media promoted the growth of pigmented colonies. Perhaps this is due to the occurrence of stressful conditions and the influence of unfavorable factors, in the event of which pigments are involved in defense mechanisms. On medium with a high content of nitrogen-containing components (FPA), the growth of microorganisms was 


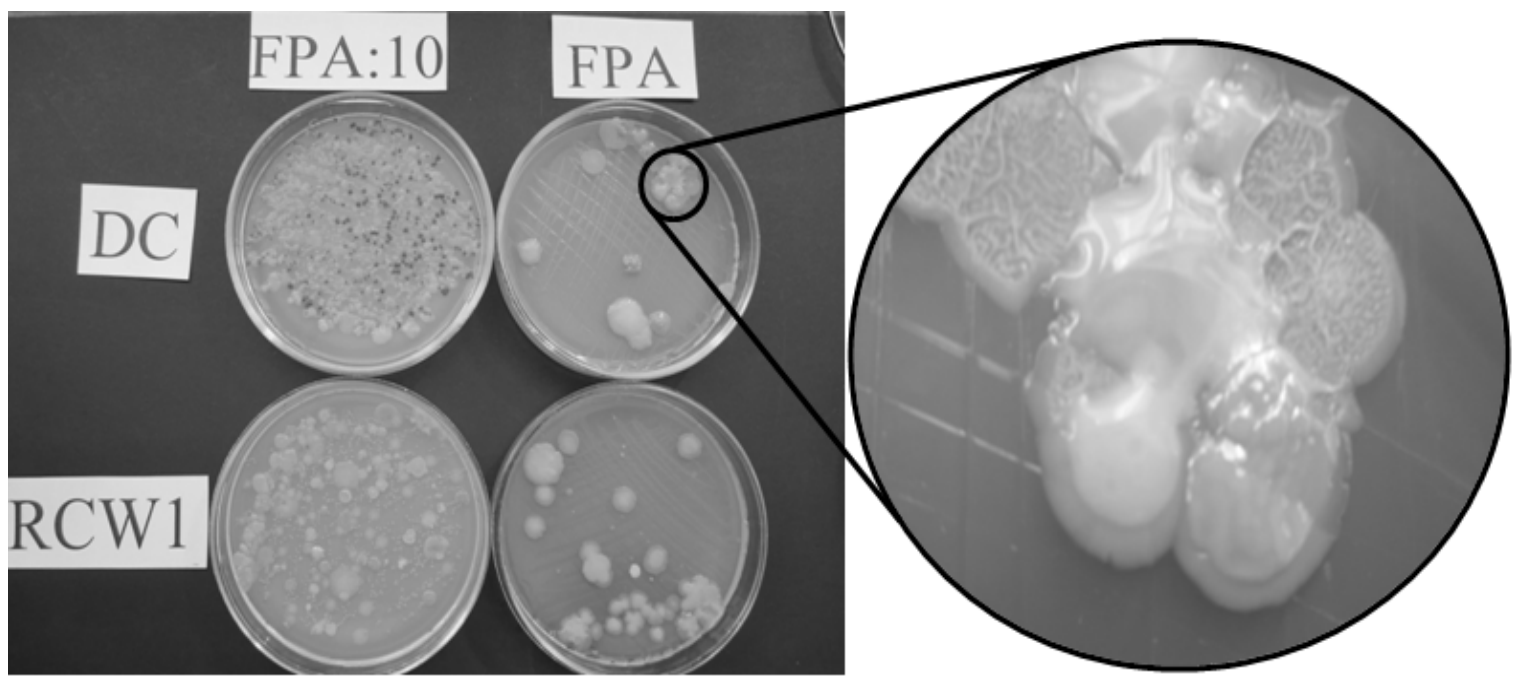

Fig. 2. Characterization of biofouling microbial complexes from a decarbonizer (DC) and from the walls of a reservoir of clean water (RCW), growing on fish-peptone agar (FPA) and FPA, diluted 10 times (FPA: 10).

accompanied by the formation of unpigmented large, paleyellow colonies (Fig. 2). This indicates a direct effect of the nutrient source on the structure and morphological characteristics of microorganisms included in biofilms. An important feature in the formation of biofilms is the synthesis of the polysaccharide matrix by bacteria. In our case, the bulk of the biofilm was presented by the exopolymer matrix (EPM), which accumulated in the RCW during the entire period as a result of the vital activity of bacteria newly supplied with water. EPM is an essential component for bacterial adhesion under constantly changing hydrodynamic conditions. It has been established that EPM plays an important functional role in complex biofilm communities; they account for up to $20 \%$ of the biomass [10]. EPMs are a mixture of high molecular weight compounds, which may include polymers secreted by living microorganisms and the contents of cells after lysis.

\subsection{General characteristics of the isolated strains}

On agar nutrient media (FPA:10, FPA), about 20 strains were isolated from RCW and DC biofilms. Isolation of individual strains made it possible to determine their cultural characteristics and trophic preferences. As a result of light microscopy, it was found that the structure of fouling MCs includes mainly Gram (-) rod-shaped cells with a pronounced capsule. Colonies abundantly producing mucous polymers were represented by glued single cells with capsules. Pigmented colonies, after subsequent platting on agar media, lost their ability to pigmentogenesis, but retained the ability to synthesize biopolymers. Characteristic feature of the isolated strains was their intensive growth on a rich nitrogen-containing FPA medium and the formation of various R- and S-forms of colonies. Strains isolated from the biofilms of DC and RCW were cultivated on Bromfield's medium with various additives: peptone $(2 \mathrm{~g} / \mathrm{L})$, glucose $(3 \mathrm{~g} / \mathrm{L})$, lactate $(2 \mathrm{~g} / \mathrm{L})$, and sodium humate $(0.025 \mathrm{~g} / \mathrm{L})$ to determine the nutritional requirements. Most strains preferred the readily available nitrogen-containing carbon source, peptone. On this substrate, active growth and mucus formation is recorded. However, only individual strains isolated from DC grew on the humic preparation and lactate. Cultural characteristics indicate a high adaptive potential of microorganisms included in the structure of biofilms from $\mathrm{DC}$ and RCW. Regardless of the nutrient source, the formation of a mucous exopolymer matrix was observed in most biofilm-forming representatives. Pigmentation occured in specific biofilm strains contributes to the activation of the protective function of microorganisms under unfavorable conditions (for example, a decrease in the concentration of nutrients or exposure to disinfectants).

\subsection{Microstructure of RCW biofilms}

Scanning electron microscopy (SEM) revealed spiral formations with increased iron content in the biofilms, which may belong to the iron-oxidizing bacteria Gallionella spp. (Fig. 3). These bacteria can grow at neutral $\mathrm{pH}$, low water temperature and aeration conditions, when the chemical oxidation of iron is slowed down by inhibiting its autocatalytic oxidation. It can be assumed that, under specific conditions, Gallionella is extracted from the aquatic environment of iron traces with a lack of oxygen at the bottom of the reservoir. It is known that fibers twisted in the form of spirals are capable of depositing iron ions Fe (III) on themselves; the fiber core is a carbon matrix surrounded by bacterial polymers [11].

In addition to spiral structures, long rods with contrasting discs at one of the ends, reminiscent of ironoxidizing bacteria of the genus Leptothrix, were found in large numbers in the RCW fouling.

Among them there is a specialized group of bacteria with attachment discs that accumulate iron and form ironcontaining sheaths or sheaths on the cell surface (Leptothrix ochracea, Leptothrix discophora) [11]. Scanning electron microscopy made it possible to identify in the mucous sediment not only representatives of ironoxidizing bacteria, but also protozoa, including a unique group of cosmopolitans - testate amoeba (Fig. 3). 


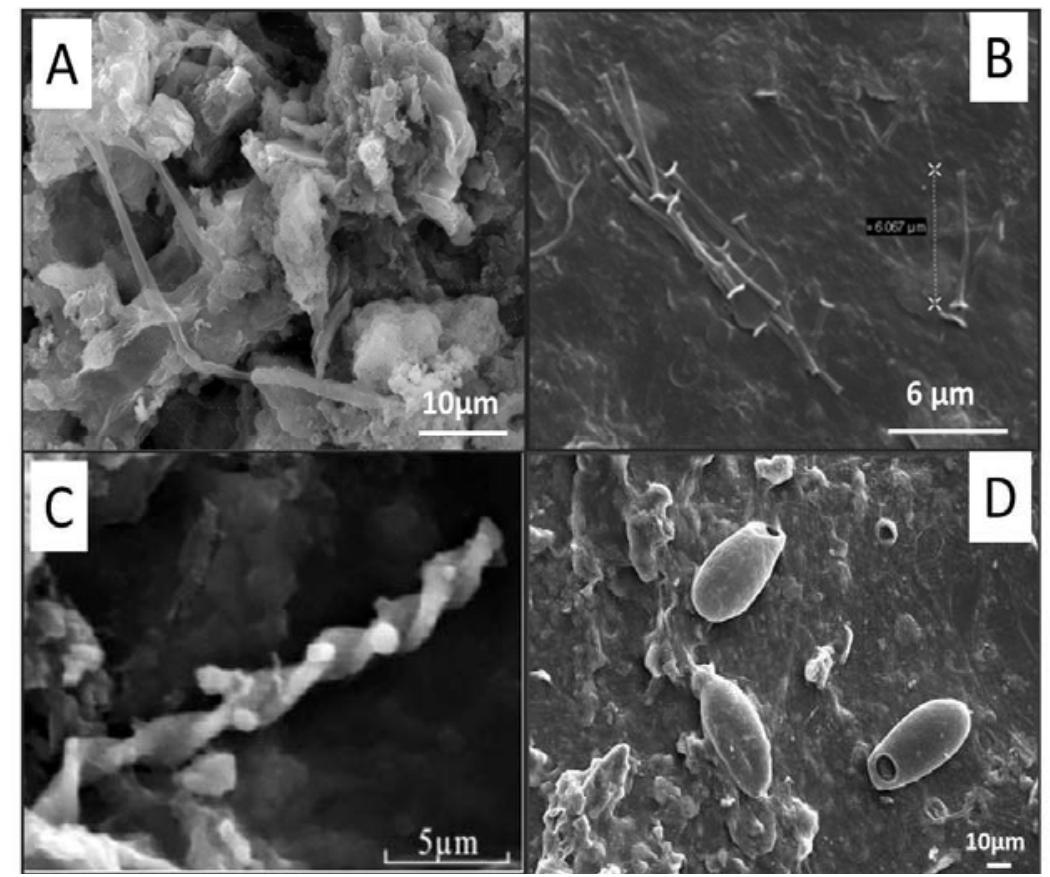

Fig. 3. SEM images of fouling microbial community from a reservoir with water: A—biofilm locus; B—Leptothrix sp.; C— Gallionella sp.; D-Trinema amoeba.

According to morphological features, some representatives of protists found in biofilms sampled at the bottom of the RCW are close to the representatives of Trinema amoebae.

\section{Conclusions}

Studies have shown that during groundwater treatment in the decarbonizer and reservoir of clean water, fouling (biofilm), represented by the community of cultivated heterotrophic and chemolithotrophic bacteria, is formed. They can grow in terrestrial communications, using micro-admixtures of organic substances as a carbon source, and $\mathrm{Fe}$ ions as electron acceptors. Main characteristic feature of the fouling microorganisms from decarbonizer was the ability to pigmentation and the formation of a slimy polymer matrix. Complex microbial communities can form at the bottom of clean water reservoirs, which are represented by bacteria, mycelial forms, and testate amoebae. Such consortia of fouling have a pronounced trophic structure, the functioning of which can affect the quality of water due to the release of metabolic products. Identification of factors influencing the formation of fouling at each stage of water treatment will create an additional barrier to protect drinking water from contamination by accompanying microorganisms and prevent changes in its organoleptic characteristics.

\section{References}

1. WHO, Water Safety in distribution systems. (WHO Press, 2014)

2. U. Szewzyk, R. Szewzyk, W. Manz, K.H. Schleifer, Ann. Rev. Microbiol. 54 (2000)

3. V.V. Kulakov, L.M. Kondratyeva, Russ. J. Pac. Geol. 1 (2008)
4. E.V. Seredkina, V.G.Teslya, Water supply and sanitary engineering, 1 (2009)

5. V. Merwe, S. Duvenage, L. Korsten, J. Water Health. 11, 1 (2013)

6. E.N. Obiofu, O.H. Ige, E.N. Chikezie, GSCBPS, 5, 3 (2018)

7. V.V. Kulakov, V.I. Steblevsky, K.V. Domnin, V.G. Teslya, J. Herlitzius Water supply and sanitary engineering, 7 (2012)

8. J. Herlitzius, H. Sumpf, T. Grischek, Int. J. Water Manag., bluefacts, 76-81 (2012)

9. B. Braun, J. Schröder, H. Knecht, U. Szewzyk, Water Res. 107, 15 (2016)

10. T.J. Stewart, J. Traber, A. Kroll, R. Behra, L. Sigg, Environ. Sci. Pollut. Res. 20 (2013)

11. T. Suzuki, H. Hashimoto, H. Ishihara, T. Kasai, H. Kunoh, J. Takada, Appl. Environ. Microbiol. 77 (2011) 